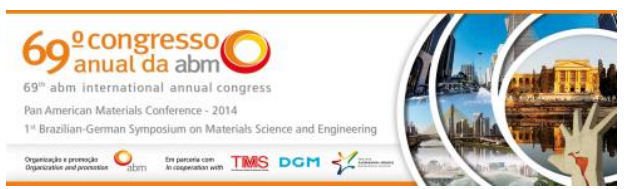

Tema: Forjamento

\title{
ESTUDO DA EVOLUÇÃO MICROESTRUTURAL DE UM AÇO MICROLIGADO SUBMETIDO A UM FORJAMENTO A MORNO*
}

Wilson Alexander Hormaza Rodriguez ${ }^{1}$ Carlos Augusto Silva de Oliveira ${ }^{2}$ Gabriel Mauricio Castro Güiza ${ }^{3}$

\section{Resumo}

O desenvolvimento da indústria automobilística exige inovações na área de materiais de engenharia assim como de processos. A partir desta necessidade, as propriedades dos aços baixo e médio carbono podem ser melhoradas com a precipitação e refino de grão associado à adição de pequenas quantidades de elementos formadores de nitretos, carbonetos e carbonitretos. Aços baseados nestes princípios podem classificar-se como aços microligados, apresentando elevados níveis de resistência mecânica e tenacidade sem aumentos significativos nos custos de fabricação. No entanto, um dos métodos de obtenção de estruturas refinadas na indústria é mediante o processamento termomecânico com o propósito de se atingir uma microestrutura predeterminada. Assim o refino obtido é baseado no controle da cinética de nucleação e crescimento de grão. Neste trabalho foi estudado o efeito do forjamento a morno no refino de grão de um aço microligado. Inicialmente, as amostras foram aquecidas a $550^{\circ} \mathrm{C}$, deformadas através de um processo de forjamento $(40 \%, 60 \%$ e $80 \%)$ e resfriadas em água. Em seguida foram recozidas na região subcrítica por tempos variando de $1 \mathrm{~min}$ a $10 \mathrm{~min}$ e novamente resfriadas em água. A evolução microestrutural, assim como o comportamento mecânico deste aço, foram avaliados através de microscopia óptica, eletrônica (varredura e transmissão) e testes de dureza. O processo de forjamento mostrou-se eficaz na obtenção de uma microestrutura refinada associada a uma recristalização da ferrita.

Palavras-chave: Aço microligado; Evolução microestrutural; Refino de grão; Trabalho a morno.

\section{STUDY OF THE MICROSTRUCTURAL EVOLUTION OF A WARM FORGED HSLA STEEL Abstract}

The development of the automotive industry demands innovation both in the engineering materials, as well as in the conformation processes. Due to these new requirements, the properties of mild steels have been improved by grain refinement and precipitation hardening. The aforementioned mechanisms are activated by minute additions of carbide, nitride and carbonitride forming elements, such as $\mathrm{Ti}, \mathrm{Nb}$ and $\mathrm{V}$. The resulting steels are classified as High Strength Low Alloy (HSLA), combining high strength with low production cost. An additional way of inducing a grain refinement in these materials is through a thermomechanical process, specifically designed to obtain a predetermined structure. There, the grain size is reduced by a careful control of the nucleation and growth kinetics. In this research, the effect of warm forging in grain refinement of a HSLA steel is evaluated. Initially, some samples were heated to $550^{\circ} \mathrm{C}$, following several degrees of deformation $(40 \%, 60 \%$ and $80 \%$ ) and quenching in water. Subsequently, they were subcritically annealed for a time ranging from 1 minutes to 10 minutes and, finally, cooled again in water. The microstructural evolution and the mechanical behaviour of these steel were evaluated through optical microscopy, scanning and transmission electron microscopy, and hardness testing. The warm forging process was effective in obtaining a refined microstructure associated to the ferrite recrystallization.

Keywords: HSLA steel; Microstructural evolution; Grain refinement; Warm working.

1 Doutor em Ciência e Engenharia de Materiais, Engenheiro Mecânico, Pesquisador, Departamento de Engenharia Mecânica, UFSC, Florianópolis, SC, Brasil; wilsonhormaza@gmail.com.

2 Doutor em Ciência e Engenharia Metalúrgica e de Materiais, Engenheiro Metalúrgico, Professor, Pesquisador, Departamento de Engenharia Mecânica, UFSC, Florianópolis, SC, Brasil; carlos.a@ufsc.br.

3 Engenheiro Mecânico, estudante de pós-graduação, Departamento de Engenharia Mecânica, UFSC, Florianópolis, SC, Brasil; gm.castro72@gmail.com.

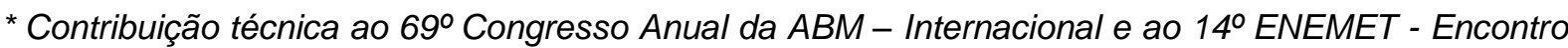
Nacional de Estudantes de Engenharia Metalúrgica, de Materiais e de Minas, 21 a 25 de julho de 2014, São Paulo, SP, Brasil.
} 


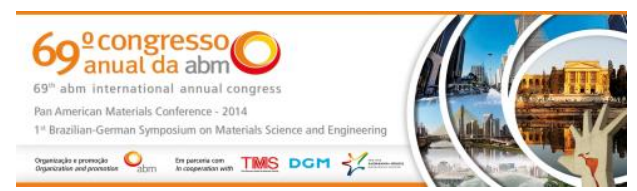

\section{INTRODUÇÃO}

A indústria automotiva está promovendo os maiores avanços em termos de materiais, buscando maior resistência, mas também com menor peso e adequação às exigências de diminuição do consumo de combustível e aumento na segurança em caso de acidentes [1]. Esse conjunto de exigências levou a que as propriedades dos aços baixo e médio carbono fossem melhoradas mediante a precipitação e refino de grão produzido com a adição de elementos de liga com forte afinidade pelo carbono e/ou o nitrogênio, como titânio (Ti), nióbio $(\mathrm{Nb})$ e vanádio $(\mathrm{V})$. Associando estas modificações na composição química com um processo termomecânico controlado, obtém-se elevados níveis de resistência mecânica e tenacidade sem acrescentar significativamente os custos de produção [2]. Deste jeito, os aços baseados nestes princípios da metalurgia podem classificar-se como microligados ou de alta resistência e baixa liga (High Strength Low Alloy Steel- HSLA).

O processamento dos aços microligados procura gerar microestruturas que garantissem melhores propriedades dos produtos semi acabados (fabricados através de conformação mecânica por meio de processos como laminação e forjamento). Um dos métodos de obtenção de estruturas refinadas na indústria metalúrgica é através do processamento termomecânico. Assim, através de uma sequência de passes de deformação plástica e tratamento térmico, atinge-se uma microestrutura pré-determinada [3]. Dentro dos muitos benefícios decorrentes deste processamento, destaca-se o refinamento dos grãos devido à melhoria gerada tanto na resistência mecânica quanto na tenacidade da liga. Este refino é baseado no controle da cinética de nucleação e crescimento de grão.

Portanto, o processamento termomecânico exige uma evolução tecnológica com a finalidade de obter uma melhora nos resultados do processo de conformação. Um dos possíveis processos para alcançar estruturas mais finas é o trabalho a morno. Esta técnica permite uma maior precisão dimensional, uma reduzida oxidação superficial e umas melhores propriedades mecânicas ao comparar-se com o trabalho a quente [4]. Contudo, o trabalho a morno, requer um maior conhecimento dos processos de conformação e do comportamento dos materiais, visto que estas operações necessitam de maiores esforços mecânicos e frequentemente são realizadas em estruturas instáveis [5]. Então fenômenos como endurecimento, recuperação, recristalização e crescimento de grão são importantes durante o processo de conformação e, portanto devem entender-se para conformar corretamente estes aços e ao mesmo tempo controlar suas microestruturas e propriedades.

Assim a finalidade deste trabalho foi estudar a evolução microestrutural de um aço microligado (HSLA) submetido a um processamento termomecânico a morno.

\section{MATERIAIS E MÉTODOS}

Na pesquisa foi utilizado um aço microligado, produzido pela empresa Arcelor Mittal Vega Brasil em escala comercial. A composição química deste aço microligado encontra-se na Tabela 1.

Tabela 1. Composição química (\% peso) do aço HSLA estudado

\begin{tabular}{ccccccccccc}
\hline \multirow{2}{*}{ Aço } & \multicolumn{10}{c}{ Composição Química(\%peso) } \\
\cline { 2 - 11 } & $\mathrm{C}$ & $\mathrm{Mn}$ & $\mathrm{Si}$ & $\mathrm{P}$ & $\mathrm{S}$ & $\mathrm{Al}$ & $\mathrm{Cu}$ & $\mathrm{Nb}$ & $\mathrm{Ti}$ & $\mathrm{Cr}$ \\
\hline HSLA & 0,0427 & 0,2730 & 0,0190 & 0,0120 & 0,0051 & 0,0500 & 0,0300 & 0,0160 & - & 0,0050 \\
\hline
\end{tabular}

* Contribuição técnica ao 69 Congresso Anual da ABM - Internacional e ao 14ํㅡㄹ ENEMET - Encontro Nacional de Estudantes de Engenharia Metalúrgica, de Materiais e de Minas, 21 a 25 de julho de 2014, São Paulo, SP, Brasil. 


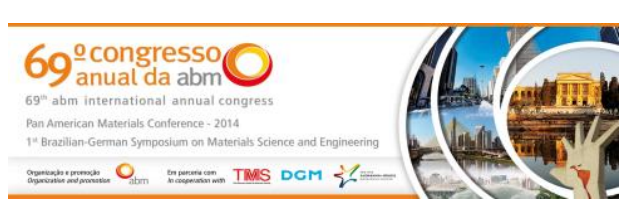

O material foi recebido na forma de chapas laminadas a quente com dimensões iniciais de $300 \mathrm{~mm}$ de largura X $400 \mathrm{~mm}$ de cumprimento e $4 \mathrm{~mm}$ de espessura. Para facilitar o manuseio deste aço durante o processamento termomecânico, foram preparados corpos de prova triangulares (com dois lados de $20 \mathrm{~mm}$ ). Assim, 0 tratamento termomecânico foi realizado em uma prensa de fricção de 150 toneladas e o aquecimento para a deformação dos corpos de prova foi realizado em um forno do tipo Mufla.

O procedimento utilizado para realização do tratamento termomecânico foi: aquecimento dos corpos de prova a $550^{\circ} \mathrm{C}$, mantendo-os nesta temperatura por dez minutos; seguidamente os corpos de prova foram submetidos a deformações em três percentuais diferentes $(40 ; 60$ e 80\%) e resfriamento em água. Logo, foi realizado um recozimento subcrítico, aquecendo os corpos de prova a $550^{\circ} \mathrm{C}$ e mantendo-os nesta temperatura durante três diferentes tempos (1; 5 e 10 min) e imediatamente após foram resfriados em água a temperatura ambiente.

As amostras metalográficas do aço microligado foram preparadas seguindo os procedimentos tradicionais já estabelecidos. A caracterização microestrutural foi realizada com o auxílio das técnicas de microscopia ótica (MO) e eletrônica de varredura (MEV), por meio de um microscópio ótico Olympus mod. BX60M com uma câmara digital acoplada - Olympus P11 e um microscópio eletrônico de varredura marca JEOL JSM 6390LV que tem acoplada uma microsonda de energia dispersiva (EDS). Com a finalidade de complementar a análise microestrutural, foram realizadas observações microestruturais por microscopia eletrônica de transmissão (MET) em um microscópio JEOL JEM-1011. Finalmente, foi determinado o tamanho de grão das amostras pelo método dos interceptos lineares médio, utilizando um analisador de imagens Analysis Five. Os resultados foram processados estatisticamente, o que permitiu calcular a média e o nível de confiança utilizado foi de $95 \%$.

Foram realizadas medições de dureza na superfície das chapas do aço estudado. A escala de dureza utilizada foi a Rockwell B (HRB, que utiliza uma carga de $100 \mathrm{~kg}$ ). O equipamento utilizado para o ensaio foi um durômetro Wilson Rockwell série 600. Ao mesmo tempo foram realizadas medidas de dureza Vickers nas amostras metalográficas obtidas do material base, assim como daquelas submetidas ao tratamento termomecânico definido anteriormente. Um microdurômetro marca Shimadzu - mod. HMV, com uma carga de penetração de $2 \mathrm{~kg}$ foi utilizado para as medidas de dureza Vickers. Os resultados apresentados são a média de 7 medidas individuais por amostra.

\section{RESULTADOS E DISCUSSÃO}

Os resultados obtidos neste trabalho foram analisados e discutidos de acordo com a seguinte organização:

- Material base

- Tratamento termomecânico com recozimento subcrítico.

\subsection{Material Base}

O aço microligado como recebido apresentou uma microestrutura ferrítica com presença de finas ilhas de perlita dispersa. Ao mesmo tempo foi possível observar a presença de finos precipitados nos contornos de grão, (Figuras 1 e 2). O tamanho médio de grão encontrado foi de 8,0 \pm 0,6 $\mu \mathrm{m}$.

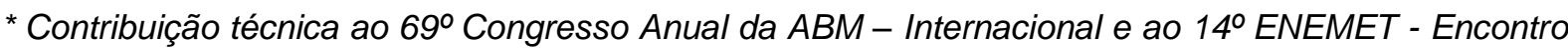
Nacional de Estudantes de Engenharia Metalúrgica, de Materiais e de Minas, 21 a 25 de julho de 2014, São Paulo, SP, Brasil.
} 

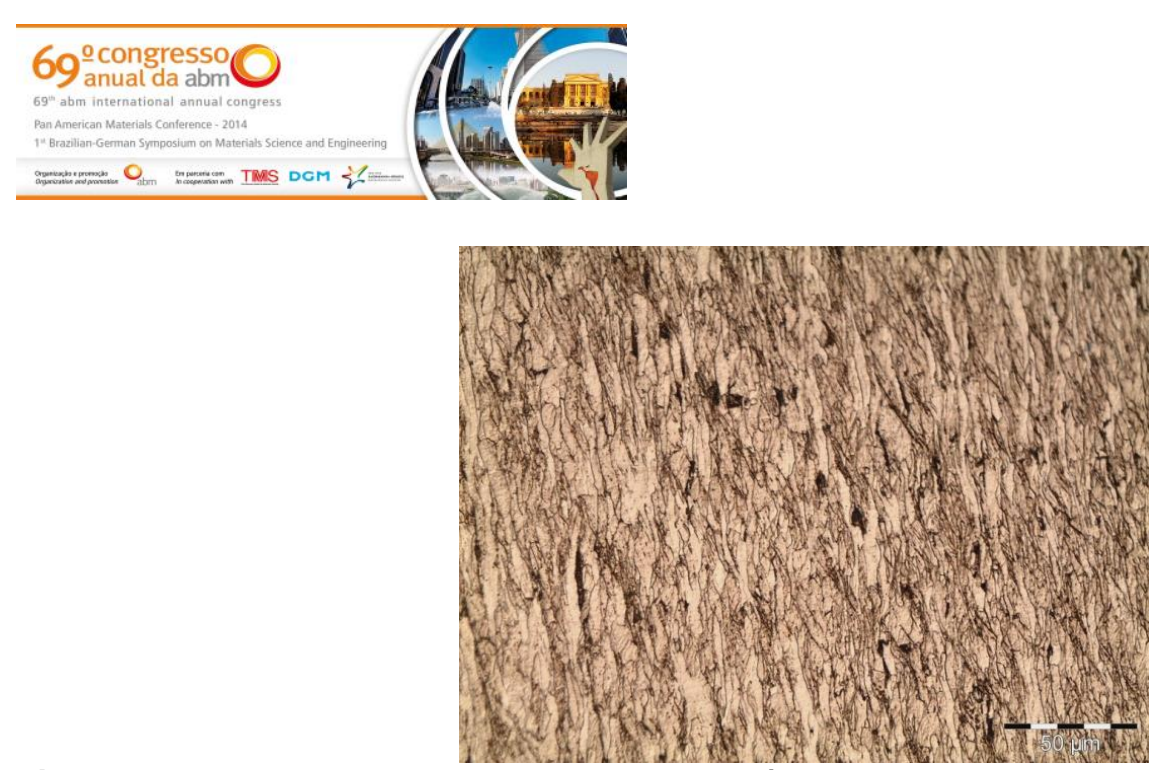

Figura 3. Microestrutura apresentando características de um material encruado (grãos alongados e bandas de deformação).

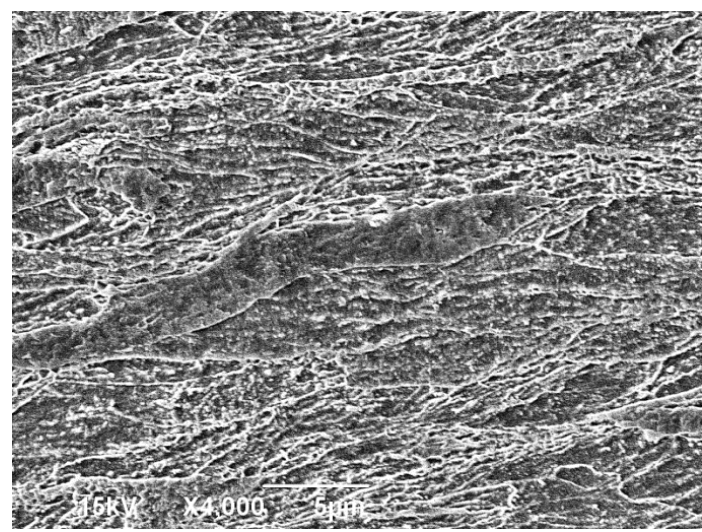

Figura 4. Microestrutura mostrando as paredes das bandas de deformação como sítios de nucleação de finos grãos/subgrãos recristalizados.

Foi observado que, à medida que aumenta o tempo de recozimento e/ou percentual de deformação, ocorre um maior grau de recristalização (Figuras 5 a 8).

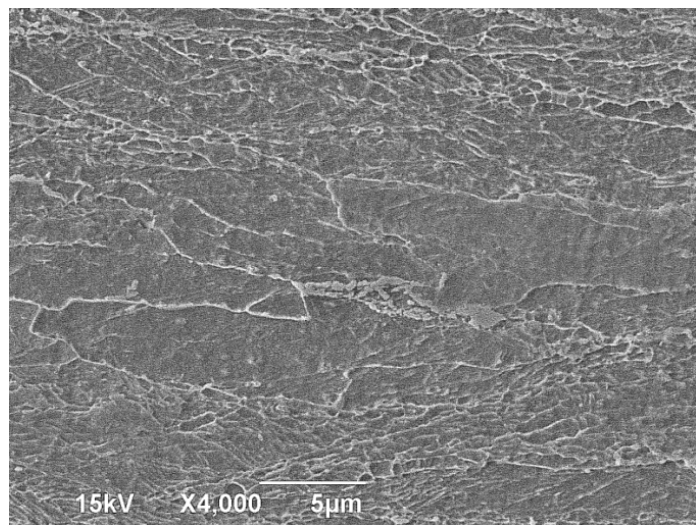

Figura 5. Micrografia revelando a nucleação de finos grãos/subgrãos recristalizados e o crescimento de grãos recristalizados (Amostra com $60 \%$ de deformação e 5 min de recozimento).

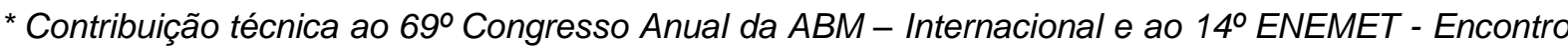
Nacional de Estudantes de Engenharia Metalúrgica, de Materiais e de Minas, 21 a 25 de julho de 2014, São Paulo, SP, Brasil.
} 

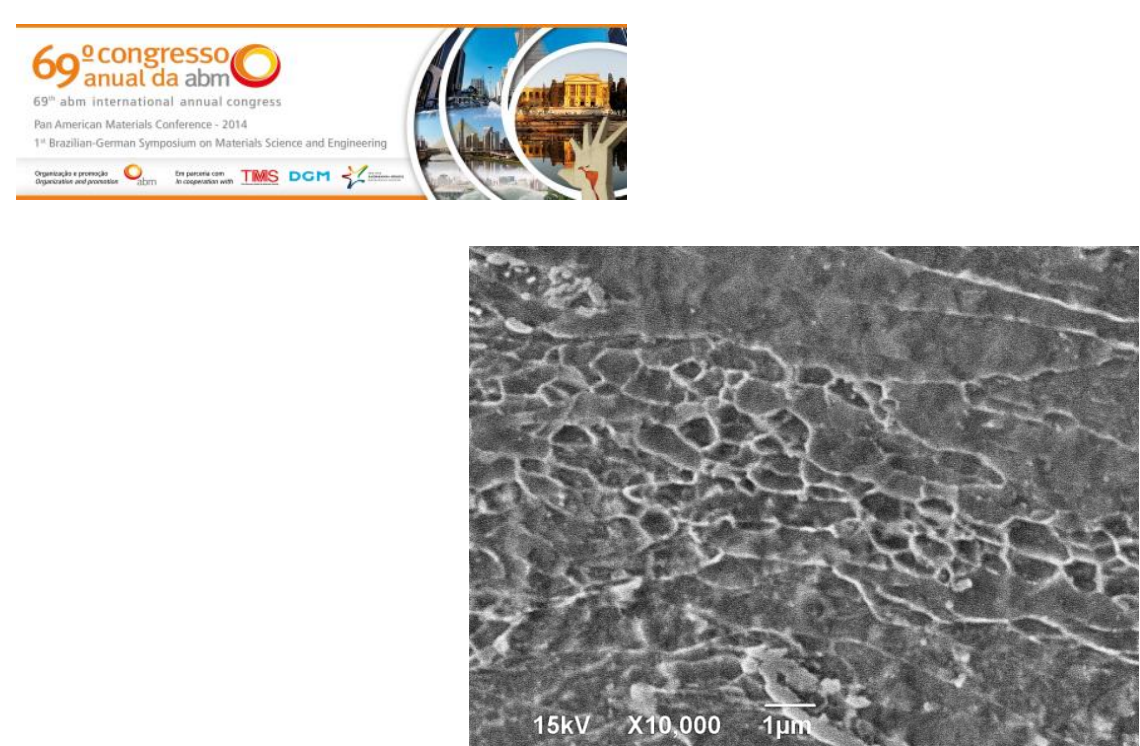

Figura 6. Ampliação mostrando finos grãos da recristalização parcial (Amostra com 60\% de deformação e 10 min de recozimento).

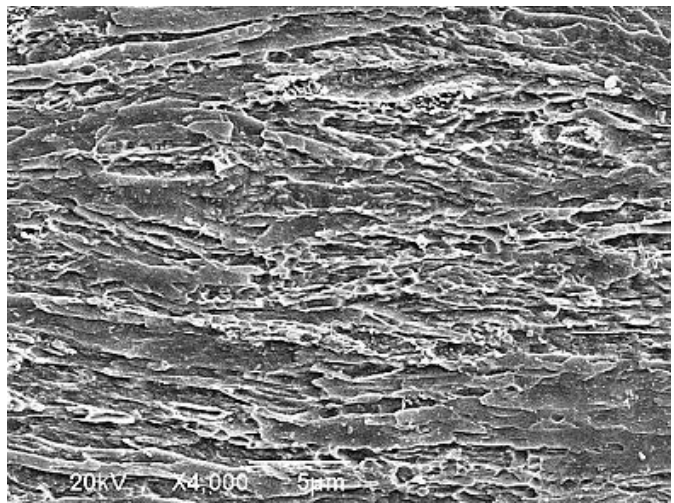

Figura 7. Micrografia indicando a presença de uma maior quantidade de grãos/subgrãos recristalizados que nucleiam nas paredes das bandas de deformação. (Amostra com $80 \%$ de deformação e 5 min de recozimento).

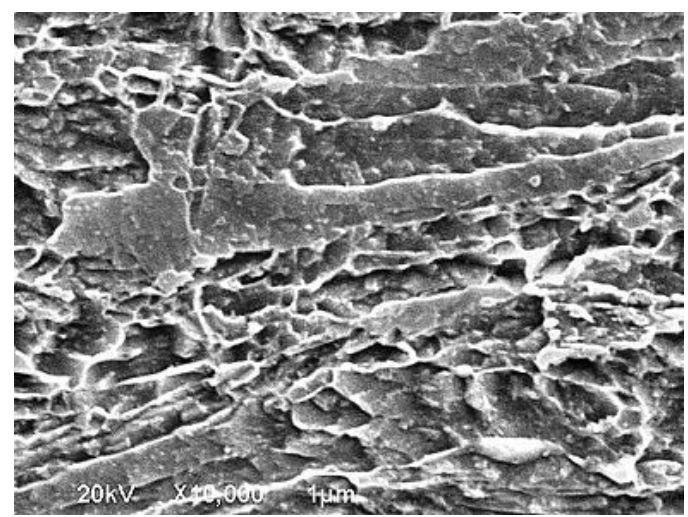

Figura 8. Detalhe dos grãos recristalizados para uma amostra com $80 \%$ de deformação e 10 min de recozimento.

Igualmente com maiores amplificações pode observar-se a presença de finos subgrãos/grãos poligonais na matriz, (Figuras 9 e 10). Ao mesmo tempo foi encontrada ao longo da microestrutura uma elevada densidade de discordâncias principalmente agrupadas nos contornos e no interior dos subgrãos/grãos.

Durante os primeiros instantes do recozimento subcrítico também foram observados finos precipitados distribuídos na matriz. Assim à medida que aumenta o tempo de recozimento ocorre um coalescimento dos precipitados, preferencialmente nas paredes das bandas e nos contornos de grão/subgrão e como consequência observa-se uma diminuição na quantidade destes finos precipitados (Figuras 11 e 12).

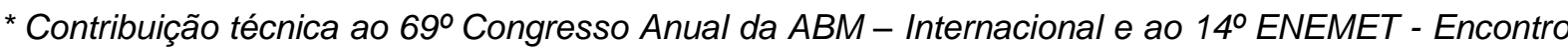
Nacional de Estudantes de Engenharia Metalúrgica, de Materiais e de Minas, 21 a 25 de julho de 2014, São Paulo, SP, Brasil.
} 

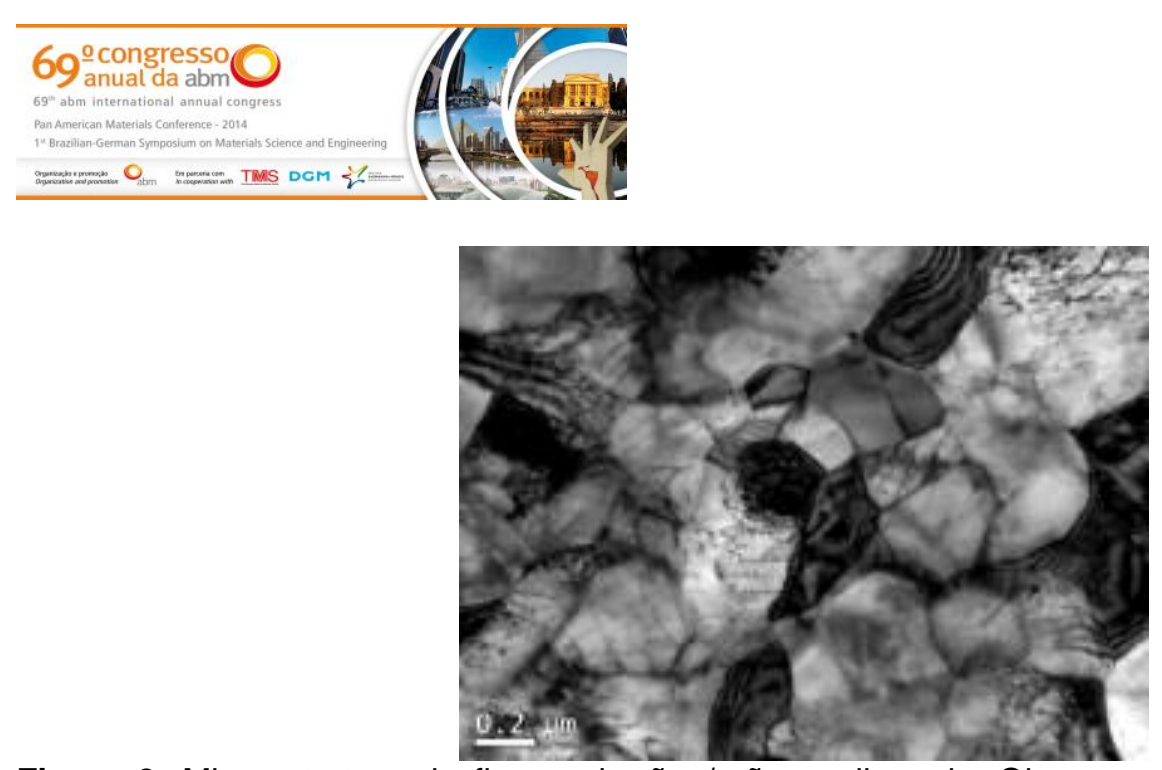

Figura 9. Microestrutura de finos subgrãos/grãos poligonais. Observam-se discordâncias (Amostra $60 \%$ de deformação e 10 min de recozimento).

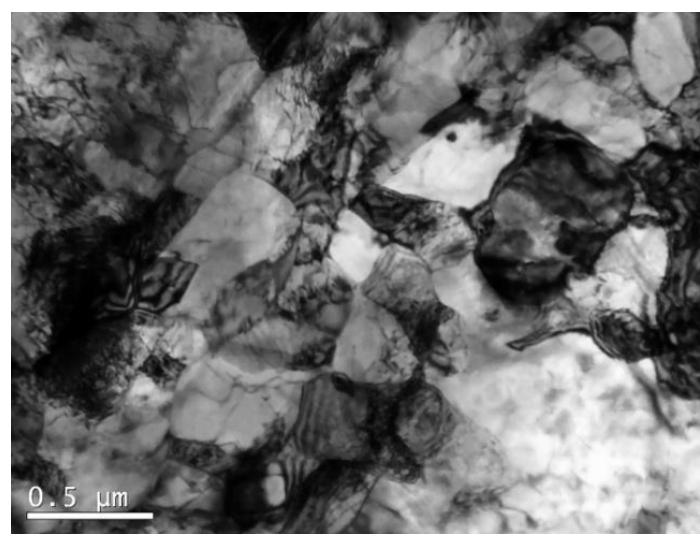

Figura 10. Micrografia de grãos e subgrãos finos com a presença de discordâncias, (Amostra $80 \%$ de deformação e 10 min de recozimento).

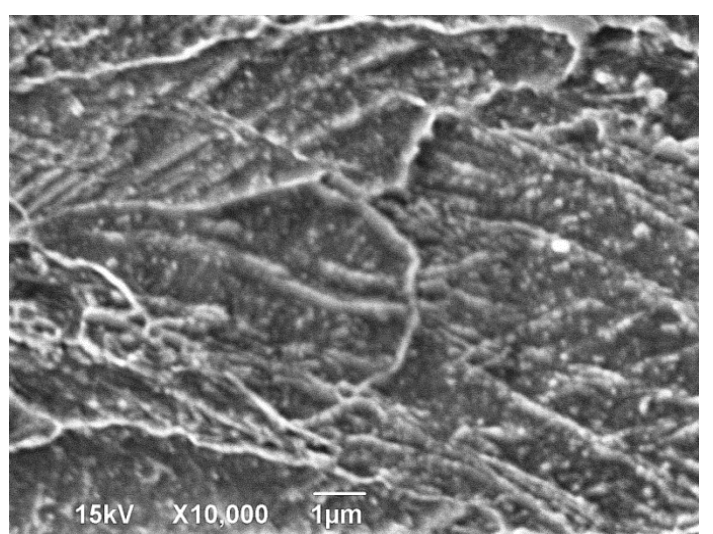

Figura 11. Microestrutura mostrando a presença de finos precipitados na matriz e coalescimento de alguns precipitados nos contornos de grão/ subgrão nas bandas.

Ao mesmo tempo foi observada uma subestrutura no interior dos grãos/subgrãos, originada pela presença de discordâncias, (Figura 13). Utilizando a técnica de campo escuro (Figura 14) é confirmada a existência de precipitados nos contornos de grão/subgrão.

\footnotetext{
* Contribuição técnica ao 69 Congresso Anual da ABM - Internacional e ao 14ํㅡㄹ ENEMET - Encontro Nacional de Estudantes de Engenharia Metalúrgica, de Materiais e de Minas, 21 a 25 de julho de 2014, São Paulo, SP, Brasil.
} 
